\title{
Civil Engineering Major Development with the Idea of Emerging Engineering Education for Provincial University
}

\author{
Xie Qun* \\ School of Civil Engineering and Architecture \\ University of Jinan \\ Jinan, 250022, China \\ E-mail: cea_xieq@ujn.edu.cn
}

\author{
Yang Tao-chun \\ School of Civil Engineering and Architecture \\ University of Jinan \\ Jinan, 250022, China
}

\author{
Jiang Wei \\ School of Civil Engineering and Architecture \\ University of Jinan \\ Jinan, 250022, China
}

\begin{abstract}
The idea of emerging engineering education is currently accepted by many domestic universities which put forwards higher requirement for engineering cultivations. In this paper some existing problems in discipline construction and personnel cultivation have been presented and in order to fulfill this education ideology of student-centered and the aim of ability training for students majored in civil engineering in provincial university, it is necessary to evaluate the regional advantages, major characteristic as well as development planning. Some measurements and methods have correspondingly been suggested with the consideration of modern information technology, teaching reform, school-enterprise cooperation and professional accreditation whose purpose is to foster future engineers with composite ability in order to meet the need of social development. Engineering education accreditation could be looked as a reasonable path for major development of civil engineering under the tendency of emerging engineering education.
\end{abstract}

Keywords-Emerging engineering education; civil engineering; professional certification; school-enterprise cooperation; information technology

\section{INTRODUCTION}

The fourth-generation industrial evolution is changing the way people live and work, influencing the evolution of higher engineering education and personnel training. The future development on engineering has the following new trends: sustainable development, computing ability, big data, Internet of Things, Nano-technology and 3D printing, inter disciplinary collaboration[1-3]. According to Dr. McClelland, the founder of American ability league, the tests cores based on knowledge and skills are not suitable to predict the professional development of graduates in the future. Only the core competency is the key element of success and sustainable development for students. The competency model (CM) is being widely used in employees' training, evaluation and professional promotion in the field of business and industry in
Europe and the United States. The university is also beginning to advocate the mode of capacity-based education. The emphasis of higher education has shifted from the teaching of knowledge and skills to the cultivation of core competency in order to meet the requirements of enterprises and society development for high quality engineer[4-7]. OBE (Outcome-Based Education) is a widely accepted concept in the world which constructs a comprehensive education system around the outcome target. OBE has been originally adopted in the United States as far back as the 1980s. The Washington Agreement (WA) has incorporated the idea of OBE as the fundamental principle[8,9]. The Accreditation Board for Engineering and Technology in American (ABET) demanded that the under graduate education program that has been certificated by ABET has to provide learning outcomes that could prove the graduated students have the required skills, knowledge and performance. According to the universal standard of ABET2017, the learning outcomes should include eleven items of competency shown in Table1[10]. The National Society of Professional Engineers (NSPE) supplemented another six items which are the basic competencies for all registered professional engineers based on the ABET universal standard[11].

\section{STATUS ANALYSIS}

The major development in the tendency of emerging engineering education is an important and urgent issue for provincial universities whose roles are to serve regional economy development and to foster qualified engineers. A brief introduction of current questions has been presented as follow.

1) The course system of engineering education major in China has been strongly restrained by the major directory and the transfer between relative majors is strictly forbidden. Little adjustment has been made to meet the inter disciplinary and 
comprehensive development trend of society demand, what's more, it is incompatible with the economic transition and industrial structure up grading which leads to the knowledge that students have studied in the campus out-of-date right after they graduate. Therefore, it is necessary to update the knowledge hierarchy to better match the current demand.

2) Due to the great difference in social orientation and core interests, the driving force for engineers education between universities and enterprises is completely different. This is also the true reason that effective cooperation between school-enterprise is unavailable. On one hand, new technology and new equipment that currently are adopted in the enterprises have not been introduced in the classes, on the other hand, the fundamental quality of engineers, such as society, economy, international perspective, law, management and ethics which are the emphasis that the companies pay attention to, are not appearance in the personal training. The gap reflects the meet the new industrial and technological development.
3) At present, the relationship between teachers and students has a complex change due to the influence of social atmosphere, internet and multi-culture. Most universities focus on the financial investment in the field of infrastructures, laboratory facilities and scientific condition in order to meet the requirement for more students. However, the enhancement in soft power including moral education, academic inheritance and tradition culture has greatly weakened. In recent years, the goal of pursuing higher ranking either in major or in discipline has made teaching marginalization. Generally teacher have to face over one hundred students in a classroom, in most cases to finish the teaching task which may be their main purpose and the teacher has little time to care about whether students really learn or understand the knowledge. There is little communication between teachers and students in campus outside the class. Quite a few teachers have to devote themselves to scientific research and students engage in preparation for postgraduate entrance exam, national civil service exam, community activities and even internet games.

TABLE I. ABET UNDERGRADUATE ENGINEERING STUDENTS LEARNING OUTCOME

\begin{tabular}{|c|c|}
\hline \multicolumn{2}{|r|}{ Serial number key skills } \\
\hline 1 & knowledge application of math, science and engineering; \\
\hline 2 & experiment design, operation and data analysis; \\
\hline 3 & $\begin{array}{l}\text { design of system element to meet requirement with consideration of economy, environment, } \\
\text { society, politics, ethics, health and safety, manufacturability and sustainable development; }\end{array}$ \\
\hline 4 & serviceability in multidisciplinary teams; \\
\hline 5 & engineering problems resolving with explicitly; \\
\hline 6 & understand professional and ethical responsibilities; \\
\hline 7 & effective communication; \\
\hline 8 & $\begin{array}{l}\text { predict the influence of engineering project on economy, environment and social background with a } \\
\text { global view; }\end{array}$ \\
\hline 9 & active life-long learning; \\
\hline 10 & modern issues recognition; \\
\hline 11 & necessary technique, skill as well engineering tools usage \\
\hline
\end{tabular}

TABLE II. STUDENTS CORE COMPETENCY UNDER EMERGING ENGINEERING EDUCATION

\begin{tabular}{|c|c|c|c|}
\hline Ability category & Must have the ability & Should have the ability & Ability to have \\
\hline $\begin{array}{l}\text { Personal } \\
\text { performance }\end{array}$ & $\begin{array}{l}\text { life-long learning } \\
\text { Honest and upright } \\
\text { Active spirit } \\
\text { Professionalism }\end{array}$ & $\begin{array}{c}\text { adaptability } \\
\text { Share the vision } \\
\text { Understand others } \\
\text { Self-esteem }\end{array}$ & $\begin{array}{c}\text { Self-management } \\
\text { Time management } \\
\text { Constant force } \\
\text { Ability to change }\end{array}$ \\
\hline Knowledge ability & $\begin{array}{c}\text { mathematics } \\
\text { science and technology } \\
\text { Social Science and Humanities } \\
\text { and Arts } \\
\text { Engineering knowledge }\end{array}$ & $\begin{array}{c}\text { information Technology } \\
\text { Health and Safety Engineering } \\
\text { artificial intelligence } \\
\text { Create professional knowledge } \\
\text { of activities and processes }\end{array}$ & $\begin{array}{l}\text { Business and Finance } \\
\text { Computer and network } \\
\text { Environmental Science } \\
\text { Understanding of legal matters }\end{array}$ \\
\hline Academic ability & $\begin{array}{c}\text { Problem solving and decision } \\
\text { making } \\
\text { Critical thinking } \\
\text { System thinking } \\
\text { Effective communication }\end{array}$ & $\begin{array}{l}\text { Quantitative reasoning } \\
\text { Information literacy } \\
\text { Innovation and } \\
\text { entrepreneurship } \\
\text { Data decision }\end{array}$ & $\begin{array}{c}\text { Academic writing } \\
\text { Knowledge Management } \\
\text { Self-assessment skills }\end{array}$ \\
\hline
\end{tabular}


Cont. to TABLE II

\begin{tabular}{|c|c|c|c|}
\hline Technical skills & $\begin{array}{c}\text { Data and Information } \\
\text { Processing and Analysis } \\
\text { Network Security and Data } \\
\text { Maintenance } \\
\text { Computer programming / } \\
\text { coding ability } \\
\text { Human-computer interaction }\end{array}$ & $\begin{array}{l}\text { Interdisciplinary capability } \\
\text { ICT knowledge and ability } \\
\text { Information technology } \\
\text { Design thinking }\end{array}$ & $\begin{array}{c}\text { Statistical knowledge } \\
\text { Understanding of organization } \\
\text { and process } \\
\text { Comprehensive application } \\
\text { skills }\end{array}$ \\
\hline Social competency & $\begin{array}{c}\text { Engineering ethics } \\
\text { Communicate effectively } \\
\text { Teamwork }\end{array}$ & $\begin{array}{c}\text { Global thinking } \\
\text { Interpersonal communication } \\
\text { leadership }\end{array}$ & $\begin{array}{l}\text { Contemporary issues } \\
\text { Accept the uncertainty } \\
\text { Adventurous spirit }\end{array}$ \\
\hline
\end{tabular}

\section{SUGGESTIONS AND MEASUREMENTS}

In order to solve the current problems in emerging engineering education, the following measurements have been recommended:

1)The future development of civil engineering will adopt the EPC (Engineering Procurement Construction) mode in construction and the PPP (Public-Private-Partnership) mode in project operation and management. Prefabricated buildings will be widely used in the process of building industrialization; meanwhile BIM technology will be incorporated into the whole life-cycle of building based on the modern information of Internet plus, big data and virtual reality. Facing with the development of modern civil engineering industry, higher education in civil engineering must speed up the transformation and upgrading of specialties, promote the cross-integration of specialties and strengthen the training of composite engineering and technical personnel. Given such analysis, therefore it is necessary to add information or knowledge about materials, management, economy and internationalization into the curriculum system for the purpose of meeting the requirements of civil engineering professional training. Typical courses such as construction technology of prefabricated building, BIM technology and application, introduction of international engineering standards, advanced material in civil engineering, modern project management as well as the graduation design based on BIM or prefabricated building.

2)As a typical engineering major, there is an urgent need to reconstruct the curriculum system and reorganize knowledge contents. Each teacher has the obligation to well understand the concept of emerging engineering education and furthermore makes corresponding adjustment in his or her teaching activities to achieve training objective. It is an effective method to reduce class hours of theoretical teaching, and provide more opportunity for students' active learning which would generate a flexural environment for teacher-student interaction. In order to establish a good relationship between teachers and students, teaching reflection among all teachers needs to be carried out to strengthen teaching reform and promote the combination of information technology and teaching methods. At present, college students are the generation growing up with the Internet and they are used to learn in virtual environment with digital technology. All teaching activity should be carried out with the idea of cooperative learning, self-learning, deep learning, mixed learning, and learning community is encouraged to promote discussion between teacher and students. Modern technology and social media, such as VR, MOOC, flipped classroom, online classes, are helpful tools and methods to increase the learning effectiveness.

3)The community of engineering education must attract social resource to work together with university win-win cooperation. In the procedure of education programs revision, experts from enterprises should be invited to participate in and put forward constructive suggestions for the personnel training. What's more, the measurements of school-enterprise cooperation including coordinated teaching, project case sharing, scientific achievements transformation, jointly laboratory, practice base and technical training, could be adopted to absorb enterprises actively participate the full process of engineer education. Universities should entirely take the intellectual advantage to help company to solve the technical problems. Under the strategy background of Belt and Road, industrialization and intelligent construction industry, BIM technology, Virtual Reality and other advanced information technology is available to be applied in engineering education and many successful projects from engineering practice could be provided as teaching cases. A platform for students innovation and entrepreneurship also need to be founded.

4) The engineering education accreditation has the same core idea with emerging engineering development, thus with the goal of new engineering education engineering education accreditation could be looked as a reasonable path for major development of civil engineering. In the crucial period of industrial structural adjustment and new growth drive to replace the old ones, the leadership of civil engineering in the national policy of Belt and Road is given the responsibility to fully implement the idea of student-centered, OBE educational philosophy, continuous quality improvement, and after five years professional development the graduates can grow into qualified engineers.

\section{CONCLUSION}

Under emerging engineering education situation, provincial universities should take the local advantage to meet the need of economic development and technological innovation, especially to strengthen the cooperation between schools and enterprises. Effort has been made to enhance students' ability in employment application. As the main source of engineers export, provincial universities should be strongly responsible for cultivating students with composite abilities who could meet the requirements of future 
engineering practice. Basically the emerging engineering development is a comprehensive reform for engineering education system rather than a simple professional construction. The object is to optimize the teaching system and create high-quality resources. In order to avoid homogeneous training, fundamental knowledge system and professional theory must be established for each students for sustainable development and continuous competitiveness in the students' career development.

\section{ACKNOWLEDGEMENT}

This research is supported by the Ministry of Education University-enterprise education cooperation research project (201701074007), Shandong Province Professional Degree Graduate Teaching Case Project (SDYAL17039), Shandong Province Graduate Education Research Project (SDYY16019), University of Jinan Teaching Research Project (JZ1418)

\section{REFERENCES}

[1] Yang Zehui, Cong Yang, Zhou Guoquan. Excellent Engineer Course Teaching of the "Four Modernizations" Evaluation System [J]. Higher Engineering Education Research, 2015,2, pp. 182-186

[2] Chen Kebei, Zhou Kaifa, Ni Jiaqiang, Analysis on American Engineering Ethics Education and Its Enlightenment to the Construction of New Engineering in China [J]. Journal of Chongqing Higher Education Institute, 2017,5 (3), pp. 36-43
[3] Wu Aihua, Hou Yongfeng, Yang Qiubo, Hao Jie, Accelerate the development and construction of new engineering initiative to adapt and lead the new economy [J]. Higher Engineering Education Research, 2017, (1), pp. 1-9

[4] Yan Hongwei, Practice and conception of teaching process assessment in colleges and universities [J].News of Science and Technology Innovation, 2013,25, pp. 111-112

[5] Peng Yanzhou, Liu Dongmei, Zhu Qiasen, Hierarchical Teaching Model of Civil Engineering Materials Experiment [J]. Higher Architectural Education, 2013,12, pp. 117-121

[6] Xia Jianguo, Zhao Jun, On the reform and development of engineering education in local universities under the background of new engineering construction [J]. Higher Engineering Education Research, 2017,3, pp.15-20

[7] Wang Yingsong, Study on Practical Teaching Reform in the Whole Course of Concrete Structure [J]. Journal of Jilin Institute of Education, 2014,11, pp.96-97

[8] Wang Yingzi, Hu Wenlong, Xiong Guangjing, Introduction of engineering education introductory course "design" inquiry teaching "Introduction to civil engineering design" as an example [J] Education Research, 2014,04,pp. 180-184

[9] Wang Guojie, Chai Min, Independent College of civil engineering graduate design teaching reform and practice [J]. Higher Architectural Education, 2013,02, pp.117-121

[10] LI Yongmei, Zhao Jun, Ma Hua, Constructing the Computer-based Teaching System of "Concrete Structure Principle" Courses Based on Engineering Quality [J] .Journal of Southeast University (Philosophy and Social Science) 2012, S2, pp.140-143

[11] Guo fei, Liu Yunan, To carry out the process of assessment model to encourage students to consciously learn [J]. Heilongjiang Education, 2015,6, pp.7-8 